\title{
ECTD Form Type Terminology
}

National Cancer Institute

\section{Source}

National Cancer Institute. eCTD Form Type Terminology. NCI Thesaurus. Code C97184.

Terminology developed to support eCT D Form Types. 